\title{
Structural Separation in Telecommunications: A Review of Some Issues
}

\section{Steven Dounoukos and Angus Henderson}

I

$\mathrm{n}$ recent years, competition authorities and telecommunications regulators have indicated an increasing willingness to consider structural separation and divestiture of the local loop as a means of countering what is viewed as serious anti-competitive activity by incumbent operators. The issue of structural separation has gained some prominence in the aftermath of the competition reforms that followed the National Competition Policy Report by the Independent Committee of Inquiry (1993) chaired by Professor Fred Hilmer. The report questioned the exemption of public monopolies from competition laws and favoured structural separation of incumbents as a way of introducing competition in monopoly markets of state-owned utilities.

A major plank of the implementation of liberalisation policies in major markets such as energy, transport and telecommunications, has been the tendency to favour the provision of access to essential infrastructure facilities owned by incumbents as a way of achieving competition in the supply of final products. This has meant that incumbent, vertically-integrated operators supply services or facilities as inputs to the production of final services by competitors with which they compete directly with the incumbent. Consequently, by their ownership of essential facilities which they supply to competitors, incumbent operators are in a powerful position in the market and have a considerable incentive to use their market power to frustrate competition. Regulation of the behaviour of incumbents, therefore, is essential for effective competition.

Reliance on access regulation alone to promote competition and prevent abuses of market power by incumbents requires extensive intervention and oversight by regulators. This arises from the fact that access regulation does not alter the incentives for uncompetitive behaviour by incumbents. Supplementation of access regulation with structural separation, on the other hand, would remove or greatly reduce the incentives for uncompetitive behaviour such as the denial of access to essential facilities and would be more likely to produce desirable outcomes without the need for extensive involvement of regulators. Because of its desirable effects, structural separation has been implemented as part of the access arrangements in several industries including electricity, gas, rail and airports. In contrast, telecommunications liberalisation has not included structural separation.

Steven Dounoukos is a Lawyer and Angus Henderson is a Partner specialising in telecommunications at corporate, communications and technology law firm, Gilbert + Tobin. 
Internationally, the Committee on Competition Law and Policy of the Organisation for Economic Co-operation and Development (OECD) has advocated structural separation to curb anti-competitive conduct of incumbent operators within regulated industries (OECD, 2001). However, a recently released draft report by the OECD's Working Party No. 2 on Competition and Regulation concluded that that there is insufficient evidence in support of structural separation (OECD, 2003).

In Australia, structural separation has received some endorsement as a regulatory solution to the perceived failures within the telecommunications market in a paper 'Reforming Telstra' by the Shadow Minister for Communication, Lindsay Tanner MP (2002). As a reaction to that paper, the Minister for Communications, Information Technology and the Arts, Senator Richard Alston, requested the House of Representatives Standing Committee on Communications, Information Technology and the Arts (2002) to inquire into the structural separation of Telstra's core network from its other businesses. The Committee was to report to Parliament by 24 March 2003. However, following a more recent statement by Tanner (2003) indicating a shift in his position away from structural separation in favour of greater internal separation of Telstra's wholesale and retail activities, the Committee's Inquiry was abandoned.

This paper considers some issues relevant to whether structural separation of the access network activities and business of the incumbent from its non-access activities (in the form of divestiture of the local loop) is currently justified in order to promote a competitive telecommunications market at the local level. Alternative approaches - essentially forms of 'accounting separation' - are also considered briefly. The issues discussed in this paper are likely to attract increased attention in the emerging debate in regard to the future structure of Telstra, the telecommunications market within Australia, and the regulatory framework in which the industry operates.

\section{Approaches to Structural Separation}

The separation of competitive and non-competitive activities of incumbent operators can take a variety of forms involving different degrees of actual separation of assets ranging from divestiture of monopoly facilities to some form of 'internal' separation of the activities within the integrated operator.

Examples of actual structural separation of competitive and non-competitive activities of an incumbent include:

- $\quad$ club or joint ownership involving shared ownership of the non-competitive activity by companies that conduct business in the competitive activity. That is, competitive retail firms would jointly own the incumbent's wholesale division. The joint ownership by major airlines of the slot allocation function at major airports in most countries of the European Union is an example of joint ownership in practice (OECD, 2001); 
- operational separation which requires the transfer of control of the noncompetitive component - and wholesale operations of the incumbent - to an independent entity, which may be made up in a number of ways. An example of this approach can be found in the US electricity industry where an independent entity operates the transmission and distribution grids, but the incumbent retains ownership of the actual assets;

- separation into several vertically integrated companies where each relies upon the other, to some degree, in order to compete. Separation would usually be performed on a geographic basis. The essential idea here is that where customers of the downstream competitive activity have to be connected to more than one non-competitive activity, and when competitive and non-competitive activities are vertically integrated, each verticallyintegrated company that is a part of each of these activities must negotiate reciprocal access to the non-competitive activities of the other companies; and

- $\quad$ separation of the non-competitive components into several smaller parts each of which is controlled by unrelated and potentially competitive smaller companies whose performance - both in terms of service delivery and regulatory compliance - may be compared against each other. include:

Examples of 'internal' separation of the activities of an incumbent operator

- accounting separation (considered in more detail below) requiring the preparation of separate accounts for specific functions or services on a predefined basis;

- functional separation where different services or activities are performed by separately operating divisions of the same firm. This may also involve separate management for relevant divisions; and

- corporate separation where different services or activities are performed by different, although commonly-owned, corporate entities.

\section{Criteria for Evaluation}

Policy makers are seldom faced with a single option for intervention in a market and good policy making requires a consideration and evaluation of the various options to determine which is best suited to particular circumstances. Sometimes, what may be the best theoretical solution may not necessarily be best in practice. Often, the cost of implementing a solution can outweigh its benefits or produce a less beneficial outcome than alternative options. Efficient regulatory intervention, therefore, requires an evaluation of all the options and the choice of the one that leads to the best possible outcome.

The basis of any comparison between the various models for structural separation and current or future alternative forms of regulation of the incumbent must be well understood. However, comparisons of this type are made more 
difficult by the apparent absence of a comprehensive (that is, detailed) nor effective (that is, practical) approach regarding structural separation within telecommunications markets. This is compounded by the specific issues that arise once a general regulatory approach is applied to a specific country, regulatory regime and incumbent carrier.

The costs and benefits of structural separation must be closely assessed and supported by evidence. Also, it is questionable whether structural separation can be any more effective than improvements to current forms of regulation, or other less disruptive alternatives. The general lack of detail and contextual analysis in current proposals for structural separation within the telecommunications industry make it difficult to offer specific comments about whether or not structural separation may or may not be effective under certain circumstances; detail and context being necessary for any model to be tested or compared against real-world experience and data.

Even if a detailed structural separation model is offered, certain doubts persist regarding the effect that structural separation may have on telecommunications markets. Relying on the experience of other industries that have applied structural separation to the activities of incumbent carriers is not sufficient. Instead, the justification for any move to structural separation should be based on an understanding of telecommunications-specific issues.

Any analysis of structural separation must therefore begin with an assessment of the merits of the structural separation model being proposed. This is essential for a meaningful comparison of structural separation with current regulatory approaches and other regulatory alternatives that may be explored as a way of tackling the perceived problems within the market. The key issues to consider in the evaluation of the relative merits of any structural separation model are:

- Problems in the telecommunications market: The deficiencies in the telecommunications market need to be assessed in order to establish a causal link between these deficiencies and the benefits attributed to structural separation.

- Whether regulation is necessary: Before changing the regulatory regime to implement structural separation of the incumbent carrier, consideration should be given to whether commercial or other incentives can operate to make the incumbent seek structural separation voluntarily. Sufficient reasons and proof must be given that shows structural separation to be the most costeffective and practical way of addressing the perceived market failure. The evidence used to support arguments for structural separation should be scrutinised carefully.

- Current regulatory approach and its deficiencies: Similarly, the deficiencies in the current regulatory approach need to be assessed, not only to establish whether structural separation is likely to overcome them but also to assess whether it may be possible to secure some or all of the benefits of structural separation at a lower cost with improvements to the existing regulatory system. 
- Practical separation: Often overlooked are the practical aspects of separation of the physical assets of the structurally-separated entity. It is important to determine the physical asset to be separated from the incumbent's network, who will take control of this asset and how.

- Costs and benefits: Any argument supporting structural separation requires a cost-benefit analysis of the resultant changes to the market and to the regulatory environment. As a first step, details regarding the potential cost of structural separation, and who will bear these costs in both the short and long term, should be provided. This should be coupled with a clear statement of the perceived benefits that are anticipated as a consequence of structural separation of the incumbent carrier. Each of these assessments should be supported by adequate analysis and market data.

- Time frame: Any cost-benefit analysis of structural separation should include a time-line detailing the milestones, key dates and stages for these benefits to be achieved and for the costs to be borne. It should state clearly how long it will take for the process to be completed and for the benefits to be felt by the market and consumers.

- Scope: The scope of the structural separation model being implemented should reflect the specific needs of the market for which it is being designed. This requires considerations of whether vertical separation is necessary (that is, wholesale and retail), or horizontal separation should also occur (that is, restricting the number and type of businesses within which the incumbent may operate).

- Incentives to innovate: Providing incentives to innovate is an important part of the social and economic aims of market regulation. Telecommunications is a dynamic market and utilised assets require ongoing maintenance and upgrade. The separated network entity must have adequate incentives to develop its network and to innovate. It must be considered how the Government and the relevant regulatory authorities will help to promote innovation. Innovation would hopefully be achieved through the introduction of competition at the local network level (indeed, there seems to be no real alternative to this), so an understanding of how structural separation would help this process is critical to its long-term effectiveness.

- Competition and the network entity: Any argument calling for structural separation should detail how it would ensure the introduction of competition at the local level. The risks and obstacles to creating a competitive environment once the incumbent carrier had been structurally separated must be considered. For example, it would be necessary to ask why the establishment of a separate body holding the separated network assets would not simply create another monopoly over the local loop, but in the hands of a new company. What, for example, would the local loop network company be prevented from doing? Also, how would pricing regulation affect its ability to compete? In determining these issues, regulatory authorities would need to consider how the various responses to these issues impact on other important areas, such as promotion of competition and innovation. 
- Regulation of the remaining competitive parts of the incumbent: What regulatory obligations, if any, would continue to apply to the incumbent once it has been structurally separated? An incumbent may ask, quite reasonably, why the use and exploitation of the local switch, if it stays with the incumbent, should have any obligations attached to it at all.

- Pricing access: An important issue that relates to the regulation of the local loop network entity after structural separation is the pricing of access to the local loop, whether it would be regulated, and if so, how it would be regulated.

- Purpose and function: Structural separation also requires a position regarding the function and purpose of the local loop network entity and how this will define the activities in which it could take part. A level of horizontal restriction on its business may be required so that it does not misuse its power as the owner and controller of the local loop to compete in other markets or affect its end-user interests.

- Legal structure: Beyond addressing issues that relate to the interaction of the monopoly separated company within the market, with regulators and with other companies, a structural separation model must also address the key issues relating to the internal structure and governance of the local loop network company. (For example, who would control it and how would it govern itself?)

- Criteria for success: Finally, criteria for success should be set so that comparisons between the promised benefits of structural separation and the actual benefits can be measured and future alternatives (to the extent they exist beyond the point of structural separation) can be considered.

\section{Establishing the Case for Structural Separation}

Clearly, as for any intervention in a market, structural separation would only be justified if its benefits outweigh its costs. In addition, it would need to be demonstrated that greater net benefits are not possible through the implementation of some other solution.

Several important benefits have been attributed to structural separation. As noted in OECD (2003), the main benefits of structural separation in the telecommunications industry are thought to include:

- promotion of entry and innovation into the competitive market with consumers benefiting from competition in the provision of services such as local telephone services and high speed Internet;

- creation of a 'level playing field' by forcing the incumbent's wholesale arm to deal with its retail arm on the same terms that it deals with any other competitor; 
- allowing regulators to focus on the wholesale network to guarantee service quality, network reliability, and access to essential network facilities at costbased prices;

- relative simplicity when compared to behavioural remedies. It is effective as it targets the very reason for the incumbent's impact on competition within the market; that is, its vertically-integrated structure. In contrast, behavioural regulation can never be fully effective in this way as it is reactive, rather than pro-active;

- alignment of the incumbent's incentives with those of non-integrated carriers; and

- reduction of the need for regulation as incumbents have fewer incentives to abuse market power.

Varying approaches have been taken to the 'onus' of establishing the need for structural separation. Some approaches favour separation in the absence of a compelling justification not to do so (Productivity Commission, 1997). Other approaches favour a detailed analysis of the costs and benefits of structural separation prior to its implementation (Independent Committee of Inquiry, 1993). Assuming the latter approach, the following additional issues need to be considered prior to adopting structural separation.

\section{Cost-benefit analysis}

Structural separation would require the incumbent, and indeed the Government, to incur new and potentially significant costs. Whatever results a long-term costbenefit analysis of separation (versus conglomeration) may yield, there would be the immediate transitional costs associated with structural separation to take into account. Typically, these costs would be passed on to consumers either directly or indirectly through prices. This may require the incumbent to face further regulation, in particular with regard to pricing. Given that one of the objectives of structural separation is to increase competition and thereby lessen reliance on regulation, increased price regulation would appear to be somewhat inconsistent with that objective. In a regulated market, the competition authority is likely to aim to ensure that costs do not overly affect the ability of businesses to compete, grow or be profitable.

It is also important to note that the recoupment of costs associated with structural separation may take longer than the technology itself will remain profitable or viable. A cost-benefit analysis must take into account the effects of technological refresh and innovation, and the time-scale over which an investment strategy for structural separation must be made.

Given that the potential short-term and long-term costs for the incumbent and consumers may be significant, the methodology for calculating the benefits associated with structural separation must be closely analysed and quantified. 


\section{Effect of convergence and timeframe for achievement of benefits}

Digital convergence of technologies and the changing uses of telecommunications networks will continue to impact on the development of telecommunications regulation. Market power may be undermined in some areas, or created, maintained or increased in others. In this context, it will become increasingly difficult to define markets and the effect of structural separation may become difficult to predict. Depending on the time line for recoupment of costs, this may impact significantly on the ability of structural separation to pay for itself, which in turn will impact on the choice of approach to structural separation.

Clearly, structural separation must be shown to be a robust strategy that can work within a new, converged economic and technological environment. There are risks that convergence and technological change pose for the value of the local loop. Ultimately, in the general calls for structural separation, it remains unclear whether the resources needed to implement structural separation would not be better applied to the development of new infrastructure and technologies that avoid the 'last mile' bottleneck of the local loop altogether. Arguments supporting structural separation must address this issue if they are to establish structural separation as the best alternative to current regulatory approaches.

\section{Pricing and competition}

Structural separation of the incumbent carrier does not mean that new entrants providing access services would not need to compete for customers. It is highly likely that after structural separation occurs, customers seeking access would remain with the incumbent until they are competed away. It is questionable whether structural separation would have much impact given that significant commercial obstacles remain for any new entrant. The incumbent's power due to its reputation and historic relationship with customers and the market cannot be ignored.

Pricing and drivers of competition are two of the very justifications for the use of structural separation. Any argument supporting its use should emphasise, in detail, how structural separation would deal with these issues.

\section{Impact on investment and innovation}

Structural separation is likely to have an impact on investment and innovatory incentives and raise questions about future network management. A vertically integrated operator may innovate on the network side of the business with the ability to obtain a return in any part of its integrated business.

If a local access network company is created, it may have less incentive to invest in innovation where its prospect of obtaining a return on that investment is limited to its network business (and not some other part of the fully-integrated business). Government ownership of the access network company may also 
impact upon the funding made available to innovate and the risk the Government is prepared to take with such innovation.

The access network company may also be regulated in a way that provides little or no incentive to innovate through upgrading (that is, it is limited to setting access fees based on a reasonable rate of return on its existing assets without any allowance for future network expansion or upgrade). The argument being that the access network company should bear the burden of the risk of its own failure rather than passing that risk on to downstream competitors.

To be able to finance innovation and development, the access network company will need to achieve an increase in its rate of return, either through increased profits or decreased costs. Unless it can do so, it would have little, if any, reason to innovate. Hence, how this rate of return is regulated to allow for innovation but prevent gold-plating and inefficiency is a key question for the regulation of any structurally-separated entity.

\section{More rules?}

Given the deregulatory ambitions of structural separation, one would question whether there is likely to be more or less regulation post structural separation than at present. Will the market permit the incumbent to develop its own network? If this is permitted, for example, there would need to be rules about the areas of business that the access network company would be able to operate in. Would the access network company be able to develop value-added networks and services to maintain and enhance its business, at the risk of vertical integration emerging? Would vertically-integrated new entrants be permitted to set up new loops to compete against the access network company?

Arguments supporting structural separation should give close attention to what the market and regulation will look like after separation and how the access network company, the incumbent and their respective competitors might function after structural separation has occurred.

\section{Unsettled criteria for measuring success}

As previously argued, any analysis or assessment of a regulatory regime should clearly establish the basis upon which the regime is to be assessed. Clearly, the intent of regulation is to ensure that sustainable competition and economic welfare are maximised. However, by not referring to any specific benchmarks or methodologies that might help assess one regulatory approach against another, the principles remain too ambiguous to be of use in a comparative analysis of any sort. At what point in time, for example, should a regulatory approach be expected to have satisfied these criteria and what is the objective measure of its success or failure?

Structural separation, and any regime it seeks to overhaul or replace, should be held accountable to real industry benchmarks and targets, including a reasonable time line, that can itself be justified. Such transparency in the analysis 
is necessary to compare fairly what structural separation may achieve and the benefits attributed to it and, indeed, the very reasons for the introduction of the policy.

\section{Problems in the Telecommunications Market}

In countries with liberalised telecommunications markets, regulation aims to produce fair and open competition within the market place to deliver increased telecommunications services, choice and value for consumers. The maximisation of competition within markets ultimately aims to satisfy various social policy objectives. Many now consider that competition at the local loop level within telecommunications markets is not operating to satisfy the needs of consumers and society, nor delivering market outcomes, such as better services, lower prices and innovation, that were envisaged during liberalisation.

There are two major observations that are made to evidence stagnating competition within telecommunications markets:

- First, the perceived lack of progress in areas such as broadband and highspeed Internet access penetration is viewed as affecting consumers and citizens.

- Second, many consider that local loop unbundling has not occurred rapidly enough and so has not brought the anticipated improvements in competition of local loop based services.

In countries in which structural separation is gaining or has some momentum, the perceived problems of the telecommunications market are viewed as the result of the anti-competitive behaviour of the incumbent operator (Beard, Kaserman, and Mayo, 2001). In Australia, as in many telecommunications markets, the incumbent remains vertically integrated and operates in both the retail and wholesale markets.

The pervasiveness of incumbent telecommunications companies generally means that new entrants cannot avoid dealing with, or competing, against, the incumbent it in at least some capacity (usually in downstream services markets). This applies to companies creating or employing their own networks (as interconnection will become necessary between the networks at some point), as well as to companies that must access the incumbent's network to operate their business in order to supply services to end-users. At the same time, these companies find themselves competing against the incumbent for market share in either the wholesale or retail market.

The incumbent is thus in an extremely advantageous position, as all companies must access its infrastructure and larger network. Not only does it have a far more powerful bargaining position than its competitors, but also a substantial incentive to pursue obstructionist tactics in the supply of wholesale services to companies it competes with in the retail market. Like any company, it 
will seek to protect its profits and market share from competitors and new entrants.

When combined with high barriers to entry (for example, sunk costs), the need for any-to-any connectivity and features such as information asymmetries, market power in telecommunication markets is said to create the conditions for regulatory solutions such as structural separation. Consequently, there are now calls for a regulatory approach to restrain the effects of the power of the incumbent, and the incentive to act in an anti-competitive way. The key issue to be addressed is how, under these circumstances, to achieve non-discriminatory access to underlying network resources.

Before an approach to structural separation is adopted, it can be reasonably asked whether behavioural regulation of access is actually ineffective or whether it is more accurate to say that some forms of access regulation have been ineffective.

In Australia, access to essential facilities or bottlenecks, declared as such by the ACCC, is mandated under Part XIC of the Trade Practices Act 1974. While a bottleneck test is not used, the components of the overall regulatory objective to promote the long term interests of end users have the effect of regulating access to bottleneck services. These components provide for regulation of services if, to do so, would promote competition, enable any-to-any connectivity and promote the efficient use of and investment in infrastructure. Many of the declared services in Australia are those which run over or utilise the local loop (for example, PSTN access, unbundled local loop, local call resale, local transmission, digital data loops).

The access obligation applicable to mandated, or declared services under Part XIC is principally an obligation to supply on non-discriminatory terms. Nondiscrimination purports to place new entrants in the same position as the incumbent in relation to the provision of the declared service and, hence, in applicable cases to access to the local loop. This non-discrimination obligation, together with accounting separation, is said to 'mimic' vertical separation, however with the disadvantages described above.

The implementation of access to declared services in Australia relies on a negotiate-arbitrate cycle (an ex post approach, although recent amendments have introduced some half-way measures allowing for the ACCC to set benchmark terms and conditions, including prices, prior to a dispute arising (Telecommunications Competition Act 2002). This ex post approach means that access to services is only regulated and disputes determined once, and usually well after, a market failure has occurred.

The negotiate-arbitrate model used in Australia for access regulation has led to many disputes, long delays and a raft of legislative changes which attempt to patch-up this model. The arguments for structural separation in Australia have arisen in the context of a degree of frustration with this model of access. 


\section{Practical Implementation of Structural Separation}

A critical issue in applying structural separation to the telecommunications market is deciding which element of the wholesale activities of the incumbent would need to be separated for this to be achieved. Separation of the non-competitive elements of the incumbent operators from the competitive parts requires identification of the non-competitive element that must be separated in order to create the pro-competitive effects sought by regulators. With regard to the form that the implementation of this approach would take, the model that is gaining the most support is the creation and use of a separate legal entity (the access network company) to own and control the local loop.

\section{The access network company model}

Under the access network company model, ownership and control of the incumbent's access assets and business - primarily the local loop - would be separated from its services-based activities, and transferred to a new company. This new company would provide wholesale access services to other companies at a regulated price. The incumbent would then compete for all services through access to the local loop, and would contract with the access network company for its wholesale services as any other company would.

The key questions that must be considered under this approach are:

- First, what assets exactly (that is, what will be viewed as the local loop) must be separated from the incumbent?

- And then, who will take control of this asset and how will this occur?

\section{What would be separated from the incumbent?}

Structural separation in the telecommunications industry requires a definition of the scope (or 'border') of the local loop and related access elements of the incumbent's network that are to be separated.

With regard to the local loop, separation might only involve the copper wires, not just the local switch. Including the switch as part of what would be separated from the incumbent would see some services vested in the separated access network company. Therefore, it could be less complex to separate the copper wires only. If, however, the border were within the switch itself, where exactly would the defining line for the local loop fall?

Issues of key practical significance give rise to two main options depending on the extent to which the access network company would be exercising control within the switch in addition to control of the copper wires, namely:

1. control of the main distribution frame only; or

2. control of the entire switch. 
As OECD (2003) also notes, the first of these options is preferred, if it is accepted that structural separation aims to separate the non-competitive assets from the incumbent. Its primary advantage lies in the fact that it separates only the incumbent's non-competitive or bottleneck assets that lead to anticompetitive market outcomes.

The main disadvantage of the first option is that no single party would be assigned the responsibility for the operation and maintenance of the switch, which could result in complicated and difficult dealings between parties. Consequently, there would be a need to clarify how associated services relating to access to the local loop would be developed, and which parties would be allowed to provide such services.

By including the entire switch, the second option would simplify the operation and maintenance of the switch by allocating responsibility for them to the access network company. However, it creates a series of new issues as control and use of the switch would involve the provision of many value-adding services that could in themselves constitute a bottleneck. Consequently, there would be a need to address the question of whether the services that attach to the control and ownership of the local loop should be subject to competition in order to curtail the power that exclusive control of the local loop and provision of related wholesale access services would confer on the access network company. Such a situation would raise issues similar to those associated with vertical integration of the incumbent. Adoption of the second option would require the development of specific regulation for the pricing and delivery of the services, and the extent to which the access network company would be allowed to provide access services related to its ownership and control of the local loop.

The technical choice between these two options is an example of a telecommunications-specific issue that must be adequately addressed by any argument supporting structural separation within the telecommunications market. Determining the scope of the assets to be separated cannot be side-stepped and is a fundamental issue that must be addressed before structural separation can be viewed as a practical option. It is highly important, therefore, that any discussion of the potential use of structural separation be based on and reflect a practical and 'hands on' understanding of the telecommunications market.

\section{The legal structure for the structurally separated entity}

There are essentially three types of company models to consider and each of these involves a new company that would own and control the local loop (however that is defined) after divestiture from the incumbent. Beyond this common function, key variables delineate one model from the other, including issues such as ownership and control, the type of corporate governance, market regulation and a variety of other factors.

The three main approaches can be summarised as follows (Cave, 2002): 
1. A privately owned and competitive company. In this model, other companies would be free to establish their own local loop infrastructure, provided they were not dominant within the market when in vertically integrated form. Non-dominant, vertically integrated new entrants would be permitted.

2. A regulated company with a monopoly over the local loop. This model would be appropriate in situations where the telecommunications market is being privatised, but government ownership of the local loop is to be maintained even after privatisation.

3. A consortium (owned by all the telecommunications service providers in the market) with a monopoly over the local loop. Under this model, any necessary upgrade to the local loop would require the agreement of all the members of the consortium.

The three models are not necessarily mutually exclusive. It is possible, for example, for a particular market to work its way through all three approaches over the course of privatisation and deregulation. However, in markets where liberalisation relies heavily on the application of competition laws the first approach might be preferred because it involves a fully-privatised and independent company, and relies on a fair and competitive market to drive innovation, service development and price reduction.

Which of the three models is likely to be the most appropriate in a particular market depends on the market structure, government objectives and the prevailing regulatory system. Consequently, when choosing a model, careful consideration should be given to material factors that may impinge on efficient operation within the specific market or regulatory environment in which the model is to be implemented. Depending on the chosen approach, evaluation of the access network company should consider and take account of the following factors:

- $\quad$ the company's business model;

- $\quad$ its vulnerability to competition;

- $\quad$ its obligation to innovate;

- $\quad$ its size and its overheads, ongoing and maintenance costs;

- $\quad$ its cash flow;

- the services and value adding that it will be permitted to provide; and

- who may compete against it.

\section{Accounting separation as an alternative}

Accounting separation by itself is not considered sufficient for the removal of incentives for misuse of control over access to an essential facility (OECD, 2001). The keeping of detailed separate accounts of competitive and non-competitive activities however, is essential to the effective operation of an access regime. In such a situation, accounting separation will reduce the incentives for uncompetitive behaviour because it increases the risk that such behaviour will be discovered by regulators. Accounting separation, however, has little, if any, 
influence on the ability of incumbents to engage in strategic behaviour, such as delaying the provision of access to competitors, which is often used to frustrate or delay competition.

As noted by the Productivity Commission (2001), accounting separation, together with a requirement for non-discrimination when dealing with competitors, has the potential to mimic vertical structural separation. The supply of access to competitors on terms and conditions not less favourable than those applied to an incumbent's own activities is a key obligation imposed by the Australian telecommunications regulatory regime. Consequently, accounting separation for Telstra combined with an effective access regime should be able to produce many of the benefits that would accrue from actual structural separation.

Accounting separation, however, raises some important issues of implementation. The need to couple accounting separation and nondiscrimination raises concerns about whether the information collected and reported in the accounts of an accounting-separated business unit cover or, if covered, have the potential to identify discriminatory activity (see also Productivity Commission, 2001). There is a considerable information asymmetry and regulators will necessarily have to rely on the integrity of incumbents to record data accurately. While it would be virtually impossible for regulators to devote the resources necessary to ensure accurate recording of all data, the likelihood that the accuracy of the records will be checked by the regulator in the event of a dispute will act as an incentive for correct record keeping.

Some form of accounting separation has been a feature of the Australian regulatory regime in telecommunications since 1991. Since 1991, no cases of discrimination have been identified, reported or found by a regulator under this regime, notwithstanding the significant benefits associated with undetected discriminatory behaviour.

Recent amendments to the telecommunications regulatory regime in Australia require the Minister to give a direction to the Australian Competition and Consumer Commission (ACCC) about Telstra's wholesale and retail operations (section 151BUAAA, Telecommunications Competition Act 2002). Under this section, the Minister must take all reasonable steps to issue a direction to the ACCC within six months, relating to Telstra's wholesale and retail operations and requiring the ACCC to issue specific rules for Telstra's accounts. A special Telstra direction will also be subject to public consultation in a draft form and the Minister must consider any submissions received. The term 'wholesale operations' is an inclusive one relating to services Telstra supplies to itself and to others (to enable them to provide carriage or content services).

\section{Conclusion}

Supporters of structural separation within the telecommunications market advocate a significant and costly change from current approaches to regulation of the incumbent. They view an application of structural separation as justifiable on a cost-benefit analysis. However, limited evidence has been used to support this 
view. It remains unclear whether structural separation can achieve its aims in the telecommunications industry.

Specific questions that will impact on the decision to choose structural separation are:

- Do the costs outweigh the benefits?

- Will it achieve its aims?

- What factors will determine the answer to these questions, if the utility of structural separation in the telecommunications industry depends on certain variables?

- And, how should it be used and when? (For example, as a last resort only or in conjunction with other approaches.)

The issues explored in this paper cast doubt over whether there is an adequately detailed model for the structural separation of incumbent carriers that can, or ought to, be supported. In this situation, the improvement and development of alternative regulatory approaches should be investigated further. At the same time, more thought should be given to what structural separation should or could possibly involve within a specific telecommunications market.

Structural separation in the telecommunications industry raises issues particular to that industry. An analysis of the implementation issues in telecommunications illustrates that models of structural separation are not easily transferred from other industries. For example, the separation of the local loop from other competitive network elements raises technical and competition issues specific to the telecommunications industry which must be considered prior to structural separation being recommended.

Unlike other utility industries, the telecommunications industry is also a highly dynamic industry that is significantly affected by technological change. There is a constant need to upgrade the network and utilise the existing network for supply of new services. Structural separation and the subsequent regulation of the access network company may dampen the incentive for innovation in the local loop. Furthermore, given the nature of the local loop and the reasons for separating off this part of the network (that is, because of its natural monopoly characteristics), there is little or no prospect of a new entrant ubiquitously duplicating a local loop even if the existing network, over time, becomes technologically redundant.

A cost-benefit analysis is also critical. Access and interconnection regulation has costs associated with it, including the cost of regulation. However, given that access and interconnection regulation is universally seen to be essential to the success of competition, its benefits have been proven to be significant. The shortterm costs of structural separation are likely to be far more significant than the costs of access and interconnection, with the benefits largely untested.

Telecommunications regulation in Australia is currently based on an ex post model - the tools used to regulate both anti-competitive conduct and access are only effective after the offending conduct has occurred and usually after a 
considerable delay has occurred. For the reasons outlined in this paper, regulatory authorities and industry participants should view structural separation as one of several options for overcoming the difficulties and frustration associated with the existing regulatory system. Rather than considering structural separation as the only available course of action, they should also explore alternatives (for example, ex ante regulation) that are more closely related to, and build upon, existing regulatory structures that are likely to be easier to assess and implement.

\section{References}

Beard, T. R., D. Kaserman and J. Mayo (2001), 'Regulation, Vertical Integration and Sabotage', Journal of Industrial Economics 49(3):319-333.

Cave, M. (2002), 'Is LoopCo the Answer?', Info 4(4):25-31.

Independent Committee of Inquiry (1993), National Competition Policy, Report, (F. Hilmer, Chairman), AGPS, Canberra.

House of Representatives Standing Committee on Communications, Information Technology and the Arts (2002) Media release, 19 December 2002, (available at http://www.aph.gov.au/house/committee/cita/telstra/media.htm).

OECD (2001), 'Structural Separation in Regulated Industries', Report by the Secretariat DAFFE/CLP (2001) 11, OECD, Paris, 11 April.

OECD (2003), 'The Benefits and Costs of Structural Separation', Draft Report of Working Party No. 2 on Competition and regulation, DAFFE/COMP/WP2 (2003)2, OECD, Paris, 10 January.

Productivity Commission (1997), Telecommunications Economics and Policy Issues, Staff Information Paper, Productivity Commission, Canberra (available at http://www.pc.gov.au).

Productivity Commission (2001), Telecommunications Competition Regulation, Report No. 16, AusInfo, Canberra, September.

Tanner, L. MP, Shadow Minister for Communications (2002), 'Reforming Telstra', May, http://www.lindsaytanner.com/Reforming\%20Telstra1.htm.

Tanner, L. MP (2003), Transcript of Press Conference on 'Reforming Telstra', Media Monitors, 6 February.

The authors gratefully acknowledge the assistance of Dimitri Ypsilanti, Head of the Telecommunications Working Group of the OECD, who provided invaluable guidance in the development of this paper. Part of the research for this paper was undertaken while Steven Dounoukos attended a traineeship at the OECD in Paris in July and August 2002 as the recipient of the scholarship which Gilbert + Tobin offers to its lawyers wishing to pursue additional studies outside the firm. While at the OECD Stephen contributed to the OECD's research on structural 
60 Steven Dounoukos and Angus Henderson

separation and earlier versions of some of the discussion in this paper have been incorporated in OECD (2003), 'The Benefits and Costs of Structural Separation'.

The authors are also grateful to anonymous referees for helpful suggestions and to Franco Papandrea for his comments on earlier versions of this paper. The views expressed in this paper are those of the authors only and do not represent the views of the organisations they are employed by. 